\title{
Third Molar Assessment: Examiners Agreement about the Radiographically Determined Anatomical Parameters
}

\author{
Abdurrahman A. Al-Samman* \\ Department of Oral Surgery, Tikrit Specialized Dental \\ Center, Salahiddin Health Directorate, Iraq \\ *Corresponding author: Abdurrahman A. Al- \\ Samman, Department of Oral Surgery, Tikrit Specialized \\ Dental Center, Salahiddin Health Directorate, Ministry of \\ Health, Iraq
}

Received: March 14, 2017; Accepted: April 18, 2017;

Published: May 03, 2017

\begin{abstract}
Objective: This study aimed to evaluate the reproducibility of the radiographically determined anatomical parameters related to the lower third molar (L3M) by analyzing the results of examiners agreement degree.

Study Design: An observational study of 50 L3M was made from twentyfive digital panoramic radiographs, which analyzed by four examiner groups (oral and maxillofacial surgeons, dental specialists, general dental practitioners (GDP), and post-rotation dentists) through the evaluation of the position and angulation of L3M along with the root forms and their relation to the inferior dental nerve (IDN). Intra and interexaminer agreement were determined by descriptive analysis and variance test.
\end{abstract}

Results: Only evaluation of tooth angulation showed both intra and inter-group agreement among examiners $(82.3 \%, P=0.128)$, whereas mean agreement about tooth position was $80.7 \%$ for intragroup analysis with statistical significant difference to position variable in intergroup analysis.

Root form and tooth-IDN relation variables revealed lowest intragroup mean of agreement with lack of inter-group reproducibility with greater disagreement to the GDP and specialist group $(P<.05)$.

Conclusion: The intra and interexaminer reproducibility of subjective L3M evaluation was only associated to tooth angulation. These results suggest the need for using an objective measurement method to minimize the error introduced by observer interpretation.

Keywords: Examiner agreement; Third molar assessment; Anatomical parameters

\section{Introduction}

A diverse range of anatomic positions and angulations are commonly associated with lower third molar (L3M) that result in a high degree of tooth impaction [1]. Classically, L3M have been classified according to the Pell \& Gregory's and winter's criteria that classify them according to the relative depth respect to the occlusal plane, the position in relation to the mandibular ramus and the inclination of the longitudinal axis [2]. Other variables like root form and the relation to the inferior dental nerve were put in accounts by other studies [3-5]. These radiologically determined anatomical parameters have provided information influencing the precision of treatment planning.

Prediction of the extraction difficulty of $\mathrm{L} 3 \mathrm{M}$ is crucial when designing a treatment plan [6], and optimizes the patient's preparation and minimizes postoperative complications [7].

Despite the importance of Pell \& Gregory's and Winter's classifications in addition to L3M relation to the inferior dental nerve in the field of L3M surgery, a limited number of researchers were investigated the reproducibility of such classifications [8-10] and relation [11]. Moreover, and up to our best knowledge, there has been no previous research in the literature, which has tested the reproducibility of root form evaluation criteria.
Therefore, the aim of the present study was to evaluate the reliability of Pell \& Gregory's and Winter's classifications along with root form and the relation to the inferior dental nerve evaluation criteria though the assessment of the intra- and inter-group examiners agreement in different dental disciplines.

The null hypothesis is that there is no disagreement among examiners in their assessment of L3M anatomical parameters. The alternative hypothesis is that in $\mathrm{L} 3 \mathrm{M}$ anatomical evaluation, there is lack of agreement among examiners.

\section{Material and Methods}

A descriptive, observational study design was made according to the guidelines of the ethical committee of the Iraqi Ministry of Health, in which digital panoramic radiographs were selected from the database of Al-Zuhoor Dental Imaging Center, Mosul city.

The study included high-quality digital radiographs showing completely formed L3M. Those radiographs with absent lower second molar (L2M) or largely destroyed L2M or L3M were excluded. Subsequently, twenty-five radiographs were selected for inclusion in the research, totalizing $50 \mathrm{~L} 3 \mathrm{M}$ for the agreement analysis.

Before the radiographic analysis, information about the Pell \& Gregory's and Winter's classification of third molars were provided to 
Table 1: The priority of extraction difficulty-related factors as considered by examiners (\%).

\begin{tabular}{|c|c|c|c|c|c|c|}
\hline Group & Variable & Most important factor & $2^{\text {nd }}$ most important factor & $3^{\text {rd }}$ most important factor & $4^{\text {th }}$ most important factor & Least important factor \\
\hline \multirow{7}{*}{ Surgeon (1) } & Class & 20 & 50 & 30 & 0 & 0 \\
\hline & V. Position & 30 & 10 & 20 & 10 & 10 \\
\hline & Angulation & 30 & 20 & 40 & 0 & 0 \\
\hline & Root form & 20 & 20 & 0 & 30 & 10 \\
\hline & IDN relation & 0 & 0 & 10 & 20 & 40 \\
\hline & ${ }^{*}$ Others & 0 & 0 & 0 & 30 & 20 \\
\hline & No choice & 0 & 0 & 0 & 10 & 20 \\
\hline \multirow{6}{*}{ Specialist (2) } & Class & 0 & 30 & 20 & 0 & 0 \\
\hline & V. Position & 40 & 20 & 10 & 20 & 0 \\
\hline & Angulation & 30 & 30 & 20 & 0 & 0 \\
\hline & Root form & 10 & 0 & 20 & 0 & 10 \\
\hline & ${ }^{*}$ Others & 0 & 0 & 20 & 20 & 10 \\
\hline & No choice & 0 & 0 & 10 & 40 & 80 \\
\hline \multirow{7}{*}{ GDP (3) } & Class & 20 & 10 & 40 & 10 & 0 \\
\hline & V. Position & 10 & 60 & 0 & 0 & 10 \\
\hline & Angulation & 60 & 0 & 20 & 20 & 0 \\
\hline & Root form & 0 & 0 & 20 & 60 & 20 \\
\hline & IDN relation & 10 & 30 & 10 & 10 & 10 \\
\hline & ${ }^{*}$ Others & 0 & 0 & 10 & 0 & 0 \\
\hline & No choice & 0 & 0 & 0 & 0 & 60 \\
\hline \multirow{5}{*}{$\mathrm{JD}(4)$} & Class & 10 & 20 & 40 & 0 & 10 \\
\hline & Root form & 10 & 10 & 10 & 30 & 20 \\
\hline & IDN relation & 30 & 10 & 20 & 20 & 10 \\
\hline & *Others & 0 & 0 & 0 & 0 & 10 \\
\hline & No choice & 0 & 0 & 10 & 20 & 50 \\
\hline
\end{tabular}

GDP: General Dental Practitioners; JD: Junior Dentists.

*: L3M crown condition, periodontal space, bone density, or pathology.

all examiners ensuring that this study was to estimate the agreement degree among examiners. In addition, Examiners asked to list down the factors (from most to least important) considered on radiograph when evaluating extraction difficulty. These digital radiographs were printed on photo paper (at a resolution of $150 \mathrm{ppi}$ ) and numbered from 1 to 25 , then analyzed separately by 40 examiners to evaluate the position (vertical and horizontal) and angulation of L3M according to the Pell \& Gregory's and Winter's criteria in addition to the root forms and their relation to the inferior dental nerve (IDN). The following options given for root form: convergent, straight, divergent, and bulbous. Distant, close proximity, contact/seems contact were the options of tooth relation to IDN.

The examiners set in four groups; ten for group. First group comprising oral and maxillofacial surgeons (the average of their experience is 9.7 years), second group including dental specialists (10.8 years of experience), general dental practitioners in the third group (9.2 years of experience), and post-rotation junior dentists included in the group 4 (1.8 years of experience). Each examiner had a copy of digital radiographs to be compiled one week later with his/ her own evaluation recorded on answer sheet.

The data was analyzed using IBM SPSS Statistic 23 (SPSS Inc., Chicago, IL, USA) applying the following statistical tests: Analysis of variance (One-way ANOVA test) was applied to know if there was intergroup significant difference (the level of significance set at 5\%). Only in the statistically significant variables, a post-test (Duncan Test) was used to identify which examiner group demonstrated disagreement. The intragroup agreement of examiners was evaluated by descriptive analysis where mean value $\geq 0.90$ indicates excellent agreement, mean values of 80-89.9 reflects very good agreement, mean values of 70-79.9 represents good agreement, while values $<70$ indicates moderate-poor agreement.

\section{Results}

When evaluating the extraction difficulty factors as recorded 
Table 2: Intragroup agreement for different variables (mean).

\begin{tabular}{|c|c|c|c|c|c|}
\hline Group & Horizontal position (Class) & Vertical position & Angulation & Root form & IDN relation \\
\hline Surgeon (1) & $76.40 \%$ & $82.20 \%$ & $85.60 \%$ & $79 \%$ & $74.20 \%$ \\
\hline Specialist (2) & $82.40 \%$ & $81.20 \%$ & $78.80 \%$ & $72.20 \%$ & $58.40 \%$ \\
\hline GDP (3) & $79 \%$ & $84.10 \%$ & $83.80 \%$ & $61.60 \%$ & $65.40 \%$ \\
\hline $\mathrm{JD}(4)$ & $76.80 \%$ & $83 \%$ & $80.80 \%$ & $77.40 \%$ & $66.80 \%$ \\
\hline Mean of agreement & $78.70 \%$ & $82.60 \%$ & $82.30 \%$ & $72.60 \%$ & $66.20 \%$ \\
\hline
\end{tabular}

GDP: General Dental Practitioners; JD: Junior Dentists.

by examiners, the most important one was the tooth angulation as reported by $37.5 \%$ of examiners followed by vertical tooth position, relation to the IDN, horizontal tooth position, and root form $(25 \%$, $15 \%, 12.5 \%$, and $10 \%$ respectively). Table 1 illustrates the priority of extraction difficulty factors as considered by examiners. The estimation of extraction difficulty demonstrated that junior dentists recorded the highest mean value (5.98) whereas the GDP reported the least mean value (4.61). Surgeons and specialist groups recorded comparable results $(5,5.28)$.

\section{Intragroup agreement}

By analyzing the data within the answer sheets, it was possible to observe that a very good intragroup agreement recorded for the Pell \& Gregory's classification (vertical position). A comparable result seen for Winter's classification (angulation). Nevertheless, for the Pell \& Gregory's classification (horizontal position) the degree of intraexaminer agreement was slightly less. There was a good intragroup agreement concerning root form except for general dental practitioners who showed great disagreement. Evaluating tooth relation to IDN evidenced lowest degree of agreement (poormoderate) with exception of surgeon group who showed good agreement (Table 2).

\section{Intergroup agreement}

Results revealed that only the Winter's classification system did not show a significant differences in the means $(p=0.128)$, however a value of $p<0.05$ was identified to other variables, demonstrating absence of agreement (Table 3 ).

\section{Discussion}

Precise preoperative evaluation of the L3M spatial position in respect to other anatomical structures is essential in the extraction of third molars [12]. That is why an accurate radiographic diagnosis is essential to evaluate all of the possible problems related the L3M surgery [13]. The panoramic radiograph is one of the most commonly used radiographic examinations for this purpose [14]. However, most of errors in radiographical analysis occur due to inaccurate and inconsistent landmark identification $[15,16]$.

Studies found that the difficulty in L3M extraction is directly associated with vertical and horizontal tooth position $[3,17,18]$, and with bulbous roots $[3,18]$.

When tooth angulation take in account, more postoperative complication were associated with distoangular, vertical $[17,19]$, and mesioangular impaction [20]. The position of the L3M relative to the inferior alveolar nerve was also associated with an increased risk for complications [20]. The wide range of extraction difficulty-related
Table 3: Statistical significance regarding intergroup agreement for different variables.

\begin{tabular}{|c|c|c|c|c|}
\hline Variable & $P$ value & \multicolumn{3}{|c|}{ Duncan Test } \\
\hline \multirow{2}{*}{ Class } & \multirow{2}{*}{0.001} & $A$ & $B$ & \\
\hline & & $1,3,4$ & 2 & \\
\hline \multirow{2}{*}{ Vertical position } & \multirow{2}{*}{0.004} & A & B & $\mathrm{C}$ \\
\hline & & 1,4 & 4,2 & 2,3 \\
\hline Angulation & 0.128 & \multicolumn{3}{|c|}{-} \\
\hline \multirow{2}{*}{ Root form } & \multirow{2}{*}{0} & $A$ & B & C \\
\hline & & 1,4 & 2 & 3 \\
\hline \multirow{2}{*}{ IDN relation } & \multirow{2}{*}{0} & A & B & $\mathrm{C}$ \\
\hline & & 1 & 4,3 & 2 \\
\hline
\end{tabular}

factors; as addressed by the above studies; may be the cause behind lack of agreement among examiners in this study about the most important factors influencing the extraction difficulty. The ability to predict the difficulty of $\mathrm{L} 3 \mathrm{M}$ extraction found to be vary according to the experience of the practitioner with the procedure [21]. This may explain our findings where the junior dentists and the general dental practitioners showed intergroup disagreement when they estimated the extraction difficulty.

The classifications systems of L3M need to be valid and reliable for greater accuracy in patient assessment and treatment planning [8]. However, the existent systems for classifying L3M; especially winter's and Pell \& Gregory's classification; have widely accepted without intensive scientific evaluation [10]. In this study, Winter's classification showed the highest intragroup agreement (mean agreement $=82.25 \%$ ), in addition to be the only criteria demonstrating reproducibility by inter-group analysis. The high agreement degree observed may be related to the easiness to compare the L3M long axis to that of adjacent second molar. These results were inconsistent with other studies [8,10]. Pell \& Gregory's classification demonstrated high intra-group agreement degree (mean agreement $=80.6 \%$ ) exceeding that recorded by other studies (67\% and 66.25\%) $[8,10]$, while lack of agreement was observed in inter-group examination for both tooth class and position variables $(\mathrm{P}<0.05)$.This may be related to the ability of the examiners to use the classification system appropriately rather than to the classification system itself [8]. The obtained results were in agreement with Almendros-Marqués, et al. [10] and partially agree with Lima, et al. [18]. In a study conducted by Cortell-Ballester, et al. [9], a computer-assisted system (Radio Memory software) was used for the classification of L3M and a high intra and interexaminer agreement were seen for both Winter's and Pell \& Gregory's classification. However, only two examiners were employed in the 
study. Therefore, further studies with a larger number of examiners are necessary to confirm these findings.

Radiographical root form evaluation in addition to their length and number is definitely important to find out about the potential problems and to pick up the right strategy for the tooth extraction or roots separation [22]. Due to limited ability of panoramic radiography to show all details, acceptable intra-group degree of agreement (mean agreement $=72.5 \%$ ) along with loss of inter-group agreement were observed.

The transient impairment of lower lip and chin sensation; as a complications related to L3M surgery; vary from $0.4-20.3 \%$ and owing to IAN injury. A preoperative radiographical evaluation of the true relationship between L3M and the IAN would help in predicting, and possibly avoiding, sensory impairment [23]. Researchers have described several radiographical signs indicating a possible anatomical relationship of the IAN and L3M [24,25]. Absence of detailed knowledge about these signs may be the cause behind the lowest degree of intra-group agreement (mean agreement $=66.2 \%$ ) with lack of reliability in inter-group examination. Even so, dental surgeons reported a good agreement result as they encounter L3M surgery more than other dental disciplines. Comparable results were reported by Zindi, et al. [11] but with limited number of examiners (three) and for two occasions.

The different degrees of agreement among examiners about the different anatomical parameters may be due to difference in their professional backgrounds [26,27] or could be related to diverse individual conceptions of how landmarks are defined, rather than discrepancies in education and training [28].

This study suggests the need to test the validity of the existing L3M classifications or to develop new methods to increase precision in determining the spatial position of L3M in addition to their root form and relation to IDN.

\section{Acknowledgement}

The author is gratefully thanks the staff of Al-Zuhoor Dental Imaging Center for their support.

\section{Dedication}

To the spirit of my uncle Prof. Dr. Mohamedtayed Al-layla, a person who loved science and lived with scientific researches.

\section{References}

1. Fuster Torres MA, GargalloAlbiol J, BeriniAytes L, Gay Escoda C. Evaluation of the indication for surgical extraction of third molars according to the ora surgeon and the primary care dentist. Experience in the Master of Ora Surgery and Implantology at Barcelona University Dental School. Med Oral Patol Oral Cir Bucal. 2008; 13: E499-504.

2. Diniz-Freitas M, Lago-Méndez L, Gude-Sampedro F, Somoza- Martin JM Gándara-Rey JM, García-García A. Pederson scale fails to predict how difficult it will be to extract lower third molars. Br J Oral Maxillofac Surg. 2007; 45: 23-26.

3. Yuasa $\mathrm{H}$, Kawai T, Sugiura M. Classification of surgical difficulty in extracting impacted third molars. Br J Oral Maxillofac Surg. 2002; 40: 26-31.

4. Gbotolorun OM, Arotiba GT, Ladeinde AL. Assessment of factors associated with surgical difficulty in impacted mandibular third molar extraction. J Oral Maxillofac Surg. 2007; 65: 1977-1983.
5. Juodzbalys G, Daugela P. Mandibular third molar impaction: review of literature and a proposal of a classification. J Oral Maxillofac Res. 2013; 4: e1.

6. Contar CM, de Oliveira P, Kanegusuku K, Berticelli RD, Azevedo-Alanis LR, Machado MA. Complications in third molar removal: a retrospective study of 588 patients. Med Oral Patol Oral Cir Bucal. 2010; 15: e74-78.

7. Barreiro-Torres J, Diniz-Freitas M, Lago-Méndez L, Gude-Sampedro F, Gándara-Rey JM, García-García A. Evaluation of the surgical difficulty in lower third molar extraction. Med OralPatol Oral Cir Bucal. 2010; 15: e869-74.

8. Lima CJ, Silva LC, Melo MR, Santos JA, Santos TS. Evaluation of the agreement by examiners according to classifications of third molars. Med Oral Patol Oral Cir Bucal. 2012; 17: e281-286.

9. Cortell-Ballester I, Almendros-Marqués N, Berini-Aytés L, Gay-Escoda C. Validation of a computer-assisted system on classifying lower third molars. Med Oral Patol Oral Cir Bucal. 2011; 16: e68-73.

10. Almendros-Marqués N, Berini-Aytés L, Gay-Escoda C. Evaluation of intraexaminer and interexaminer agreement on classifying lower third molars according to the systems of Pell and Gregory and of Winter. J Oral Maxillofac Surg. 2008; 66: 893-899.

11. Zandi M, Shokri A, Heidari A, Peykar EM. Objectivity and reliability of panoramic radiographic signs of intimate relationship between impacted mandibular third molar and inferior alveolar nerve. Oral Maxillofac Surg. 2015; 19: 43-48.

12. Nakagawa Y, Ishii H, Nomura Y, Watanabe NY, Hoshiba D, Kobayashi K et al. Third Molar Position: Reliability of Panoramic Radiography. J Oral Maxillofac Surg. 2007; 65: 1303-1308.

13. Monaco G, Montevecchi M, Bonetti GA, Gatto M, Checchi L. Reliability of panoramic radiography in evaluating the topographic relationship between the mandibular canal and impacted third molar. JADA 2004; 135: 312-318.

14. Chen Q, Liu DG, Zhang G, MA XC. Evaluation of the Relationship between the Impacted Mandibular Third Molar and the Inferior Alveolar Canal on Panoramic Radiograph. CJDR. 2009; 12: 37-43.

15. Miloro M, Borba AM, Ribeiro-Junior O, Naclério-Homem MG, Jungner M. Is there consistency in cephalometric landmark identification amongst oral and maxillofacial surgeons? Int J Oral Maxillofac Surg 2014; 43: 445-453.

16. Kamoen A1, Dermaut L, Verbeeck R. The clinical significance of error measurement in the interpretation of treatment results. Eur J Orthod. 2001; 23: $569-578$

17. Khanal $P$, Dixit $S$, Singh $R$, Dixit $P$. Difficulty index in extraction of impacted mandibular third molars and their post-operative complications. J Kathmandu Med Coll. 2014; 3: 14-20.

18. Carvalho RW, do Egito Vasconcelos BC. Assessment of factors associated with surgical difficulty during removal of impacted lower third molars. J Oral Maxillofac Surg. 2011; 69: 2714-2721.

19. Grossi GB, Maiorana C, Garramone RA, Borgonovo A, Creminelli L, Santoro F. Assessing postoperative discomfort after third molar surgery: a prospective study. J Oral Maxillofac Surg. 2007; 65: 901-917.

20. Bui $\mathrm{CH}$, Seldin EB, Dodson TB. Types, frequencies, and risk factors for complications after third molar extraction. J Oral Maxillofac Surg. 2003; 61: 1379-1389.

21. Ferrús-Torres E, Gargallo-Albiol J, Berini-Aytés L, Gay-Escoda C. Diagnostic predictability of digital versus conventional panoramic radiographs in the presurgical evaluation of impacted mandibular third molars. Int J Oral Maxillofac Surg. 2009; 38: 1184-1187.

22. Peterson LJ, Hupp J, Ellis E, Tucker M. Contemporary oral and maxillofacial surgery. $5^{\text {th }}$ ed. Canada: Elsevier; 2008.

23. Atieh MA. Diagnostic accuracy of panoramic radiography in determining relationship between inferior alveolar nerve and mandibular third molar. J Oral Maxillofac Surg. 2010; 68: 74-82.

24. Seward GR. Radiology in general dental practice. VIII. Assessment of lower third molars. Br Dent J. 1963; 115: 45. 
25. Howe GL, Poyton HG. Prevention of damage to the inferior dental nerve during the extraction of mandibular third molars. Br Dent J. 1960; 109: 355

26. da Silveira HL, Silveira HE. Reproducibility of cephalometric measurements made by three radiology clinics. Angle Orthod. 2006; 76: 394-399.

27. Lau PY, Cooke MS, Hägg U. Effect of training and experience on cephalometric measurement errors on surgical patients. Int J Adult Orthodon Orthognath Surg. 1997; 12: 204-213.

28. Proffit WR, Fields HW, Sarver DM. Contemporary orthodontics. $4^{\text {th }}$ ed. St Louis: Elsevier; 2006
Austin J Dent - Volume 4 Issue 3 - 2017

ISSN : 2381-9189 | www.austinpublishing group.com

Al-Samman. (C) All rights are reserved
Citation: Al-Samman AA. Third Molar Assessment: Examiners Agreement about the Radiographically Determined Anatomical Parameters. Austin J Dent. 2017; 4(3): 1074 